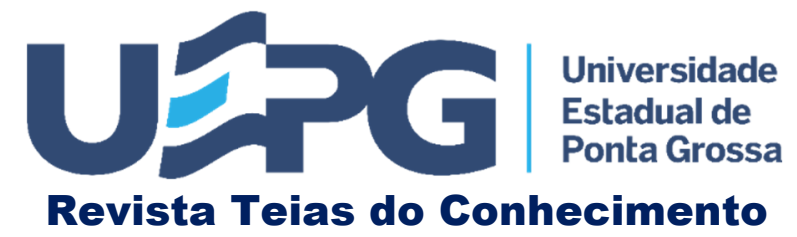

Ano 1, Numero 1, 2021

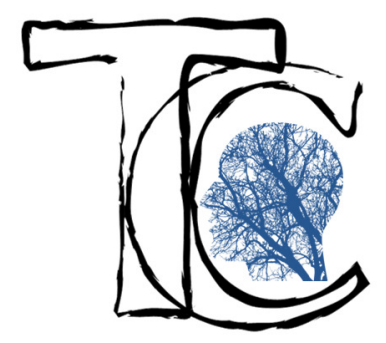

ISSN 2763-6739
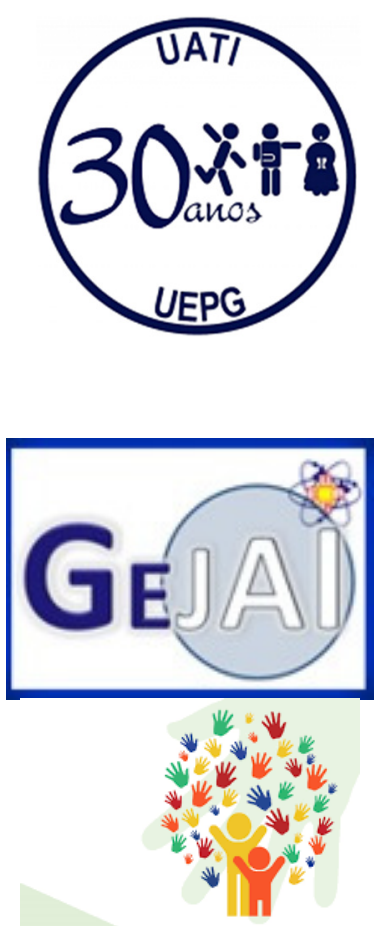

MESTRADO

EM EDUCAÇÃO INCLUSIVA

\title{
A FUNÇÃO SOCIAL DA LITERATURA NA EDUCAÇÃO INFANTIL: PRODUÇÃO DE SENTIDO E DESENVOLVIMENTO HUMANO
}

\author{
http://doi.org/10.5212/RevTeiasConhecimento.v111.20210080 \\ d. \\ Angelo Antonio Puzipe Papim*
}

https://orcid.org/0000-0002-0534-7607

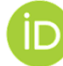

http://lattes.cnpq.br/5414579333122931

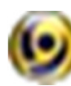

RESUMO: O homem é um ser social e, a fim de desenvolver as suas capacidades humanas, precisa apropriar-se da cultura, por intermédio de interações sociais. Nesse sentido, o processo educacional consiste em apresentar a cultura por meio do ensino intencional e motivador, o qual permite ao aluno transformar, a partir de vivências no processo de aprendizagem, as suas funções psicológicas. Assim, o desenvolvimento humano é um processo cooperativo, intergeracional, cuja comunicação materializa uma necessidade e engaja a subjetividade a entrar em atividade, dotado com a motivação indispensável para, mediante processos e ações, resolver a situação-problema e produzir sentido, na qualidade de síntese da experiência educacional. Logo, com o objetivo de compreender o processo pedagógico literatura infantil, realizou-se a análise descritiva do experimento de leitura de texto literário na Educação Infantil, enquanto mediador do aprendizado da linguagem oral e escrita das crianças. Observou-se que a linguagem está na aprendizagem das crianças, na base das funções sociais, psicológicas e, portanto, pedagógicas. A literatura é um bem cultural que precisa ser passado às novas gerações, através da leitura dos textos literários. Gera, desse modo, a necessidade de pesquisar o seu impacto no desenvolvimento humano, desde as séries iniciais.

PALAVRAS-CHAVE: Teoria Histórico-Cultural. Literatura Infantil. Interação Dialógica.

* Doutorando pela Universidade Estadual Paulista (UNESP) e Psicólogo clínico,

图 angelopapim@gmail.com 


\title{
THE SOCIAL FUNCTION OF LITERATURE IN EARLY CHILDHOOD EDUCATION: PRODUCTION OF MEANING AND HUMAN DEVELOPMENT
}

\begin{abstract}
Man is a social being and, in order to develop his human capabilities, he needs to appropriate culture through social interactions. In this sense, the educational process consists of presenting the culture through intentional and motivating teaching, which allows the student to transform, based on experiences in the learning process, their psychological functions. Thus, human development is a cooperative, intergenerational process, whose communication materializes a need and engages subjectivity to enter into activity, endowed with the indispensable motivation to, through processes and actions, resolve the problem-situation and produce meaning, as synthesis of the educational experience. Therefore, in order to understand the pedagogical process for children's literature, a descriptive analysis of the literary text reading experiment in Early Childhood Education was carried out, as a mediator of children's oral and written language learning. It was observed that language is in children's learning, at the base of social, psychological and, therefore, pedagogical functions. Literature is a cultural asset that needs to be passed on to new generations, through reading literary texts. Thus, it generates the need to research its impact on human development, from the early grades onwards.
\end{abstract}

KEYWORDS: Historical-Cultural Theory. Children's literature. Dialogical Interaction.

\section{LA FUNCIÓN SOCIAL DE LA LITERATURA EN LA EDUCACIÓN DE LA PRIMERA INFANCIA: PRODUCCIÓN DE SIGNIFICADO Y DESARROLLO HUMANO}

\begin{abstract}
RESUMEN: El hombre es un ser social y, para desarrollar sus capacidades humanas, necesita apropiarse de la cultura a través de las interacciones sociales. En este sentido, el proceso educativo consiste en presentar la cultura a través de una enseñanza intencional y motivadora, que permite al alumno transformar, a partir de experiencias en el proceso de aprendizaje, sus funciones psicológicas. Así, el desarrollo humano es un proceso cooperativo, intergeneracional, cuya comunicación materializa una necesidad y compromete la subjetividad para entrar en actividad, dotada de la motivación indispensable para, a través de procesos y acciones, resolver la situación-problema y producir sentido, como síntesis de lo educativo. experiencia. Por ello, con el fin de comprender el proceso pedagógico para la literatura infantil, se realizó un análisis descriptivo del experimento de lectura de textos literarios en Educación Infantil, como mediador del aprendizaje de la lengua oral y escrita para los niños. Se observó que el lenguaje está en el aprendizaje de los niños, en la base de las funciones sociales, psicológicas y, por tanto, pedagógicas. La literatura es un bien cultural que debe transmitirse a las nuevas generaciones a través de la lectura de textos literarios. De esta forma, genera la necesidad de investigar su impacto en el desarrollo humano, desde los primeros grados en adelante.
\end{abstract}

PALABRAS CLAVE: Teoría Histórico-Cultural. Literatura infantil. Interacción dialógica. 
A função social da literatura na educação infantil: produção de sentido e desenvolvimento humano

Angelo Antonio Puzipe Papim

\section{INTRODUÇÃO}

Os seres humanos estão se comunicando por intermédio de sistemas de símbolos há bastante tempo, na História. Como descreve Todorov (1993), a linguagem escrita foi o instrumento responsável por projetar o domínio da cultura ocidental nas culturas sem essa modalidade de linguagem. De modo geral, o texto escrito está no centro dos esforços humanos para produzir e generalizar a conduta, orientado pelo conhecimento. A literatura, como expressão dessa modalidade, constituiu-se como método cultural responsável por transmitir, para além das convenções literárias e do uso estético da linguagem escrita, os diferentes contextos socioculturais, as distintas camadas subjetivas relacionadas aos afetos e às emoções humanas, e os métodos de produzir conhecimento (CULLER, 1999).

A habilidade para comunicar, empregando símbolos, que representam objetos, ideias, ações etc., referenciais destinados a organizar a vida social, caracteriza a espécie humana. Com vistas ao desenvolvimento sociocultural, a linguagem escrita, além de introduzir o conhecimento no tempo e no espaço, oferece um conjunto integrado de instrumentos linguísticos, para pensar as práticas - alguém fazendo alguma coisa - e os objetos - coisas culturais - enquanto parte de um complexo sistema de representação, organizado ao longo do desenvolvimento da espécie humana, a fim de suprir as necessidades materiais de existência (BARROS; FIORIN, 1994; PINO, 2005).

$\mathrm{Na}$ perspectiva da Teoria Histórico-Cultural, o desenvolvimento cognitivo acompanha as mudanças que ocorrem na cultura, isto é, nos valores, nas normas sociais e nos recursos tecnológicos do contexto histórico (SHAFFER; KIPP, 2010). De acordo com Miller (2011), o desenvolvimento cognitivo da criança acontece quando esta, por meio de diálogos colaborativos com membros mais informados da sociedade, internaliza o sistema de valores, crenças e estratégias de resolução de problemas de sua cultura. A linguagem escrita, para a cultura escolar, enfatiza a maneira pela qual é possível reproduzir as práticas e os objetos da cultura, de modo a orientar ações de ensino, as quais serão canalizadas para o desenvolvimento. 
A função social da literatura na educação infantil: produção de sentido e desenvolvimento humano Angelo Antonio Puzipe Papim

A internalização de métodos de pensamento e de estratégias de solução de problemas, os quais as crianças aprendem, em função de suas interações com os membros mais experientes da sociedade, favorece a aprendizagem. O processo de ensino da linguagem escrita, que utiliza como recurso pedagógico obras literárias, tem por objetivo reconstituir no leitor, mediante o processo de leitura do livro, seja no formato físico, seja no formato digital, os símbolos e suas funções sociais, como ferramentas de desenvolvimento cognitivo (BYRNES, 2006).

As condições sociais favoráveis para a aprendizagem e o desenvolvimento humano se configuram a partir de uma série de meios de mediação, através dos quais os conhecimentos teóricos são expressos na interação social e reconstruídos como ferramentas culturais. $\mathrm{O}$ método de pesquisa e as metodologias de ensino permitem estabelecer a distinção entre o conhecimento cotidiano e as formas disciplinares pelas quais o conhecimento é produzido e difundido, no contexto escolar. A ação pedagógica deve, portanto, sintetizar na prática de ensino e de pesquisa os métodos e as metodologias como um campo de interação social no qual circulam instrumentos culturais de vários tipos, em apoio à aprendizagem da criança (DANIELS, 2016).

É no campo de interação social que as funções elementares - atenção, sensação, percepção e memória -, que nascem com a criança, são transformadas em sofisticadas funções mentais superiores. O espaço onde se dá o ensino e a aprendizagem é denominado Zona de Desenvolvimento Imanente (ZDI). Um ambiente caracterizado por condutas dialógicas, as quais visam à internalização de técnicas de solução de problemas, feitas inicialmente em regime de cooperação com parceiros mais experientes, mas que deverão ser realizadas por conta própria, demonstrando um nível de domínio dos recursos da cultura, como a linguagem escrita (ARSHAD; CHEN, 2009).

Os processos de transmissão das ferramentas da cultura, como os recursos oferecidos pela literatura e internalizados pela criança, estabelecem a necessidade de pensar, quer dizer, de submeter a processos cognitivos o que os sentidos apreendem por intermédio de imagens e signos (MORATO; $\mathrm{KOCH}, 2011$ ). Os elementos simbólicos permitem à criança ampliar a atividade psíquica, de forma consciente e 
A função social da literatura na educação infantil: produção de sentido e desenvolvimento humano

Angelo Antonio Puzipe Papim

organizada, exercendo a capacidade de julgar, de deduzir, de analisar, de planejar etc., funções psíquicas superiores boas para identificar e reconhecer os padrões e as recorrências lógicas acertadas na interação social e presentes no enredo da obra literária (WERTSCH, 2008; SHAFFER; KIPP, 2010).

Os textos e as imagens - linguagem verbal e linguagem visual -, presentes de forma abundante em livros ilustrados, caracterizam uma linguagem formada por diversos elementos (textos, imagens e suportes), cuja intersecção é capaz de produzir no leitor um modo de compreender o que se lê (VAN DER LINDER, 2011). Toda e qualquer experiência de leitura está ligada, de maneira mais estreita e direta, aos sentimentos e aos valores sociais e pessoais do leitor (WERTSCH, 1997).

A compreensão do universo simbólico se subordina a um movimento relacional, mediado por objetos da cultura, em ações colaborativas. Por esse motivo, a leitura de um texto literário, realizada em parceria com o professor, depende da centralidade e do envolvimento ativo da criança que executa a atividade. A inter-relação sociocultural é condição de uma prática dialógica e base da compreensão da relação texto e imagem (WELLS, 1999).

Como destaca Ricoeur (1988), a compreensão de um texto literário, mesmo na Educação Infantil, não consiste em descobrir um sentido por um simples modo de conhecer ou apreender um fato, mas de uma atitude de participação experimentadora, revelada através da atividade leitura. De acordo com Vygotsky (1981, 1999), o processo dialético instaurado no campo da linguagem possibilita à espécie humana firmar um processo ontológico de transformação cognitiva, condição que emerge mediante a perspectiva do outro. No interior da relação alteridade e identidade, entidades sociais que pensam e atuam com a cultura configuram uma via contraditória, repleta de significados e sentidos, de produção da compreensão (INGOLD, 2017).

No percurso de aprendizagem cooperativa, a criança não é um mero observador do texto escrito, pois não recebe dele simples informações objetivas, mas dados que precisam ser aprendidos e operacionalizados no pensamento, através 0 


\section{A função social da literatura na educação infantil: produção de sentido e desenvolvimento humano Angelo Antonio Puzipe Papim}

recurso da linguagem e da interação dialógica. A leitura, como parte de um processo de interação social, define para o leitor um posicionamento relacional com o autor e o texto escrito. Constituem-se, nessa atividade, as representações simbólicas, na qualidade de sínteses das condutas objetivadas às funções sociais correspondentes (ENGESTROM, 2014; SMAGORINSKY. 2011).

O aspecto interpessoal da leitura é responsável por apresentar mudanças sociais complexas e ferramentas para enfrentá-las. O modo de vida organizado pela palavra, um complexo sistema cultural organizado em linguagem, tem o potencial de ser incorporado ao pensamento do leitor. Cada palavra representa uma função social, e a função social é uma ideia que está incorporada à palavra. A disposição na qual as palavras são ordenadas, nas relações dialógicas, estabelece a base de uma gramática solidária, cuja estrutura se repete internamente quando a palavra, carregada de uma função social, se funde ao pensamento, tornando-se uma ferramenta de organização psicológica, transformadora das funções naturais em superiores (KOSULIN, 1990; ENGESTROM, 2016; MOEN; NES, 2012).

A capacidade humana de transformar a sua relação com o meio ocorre mediante o desenvolvimento das funções psicológicas superiores. Desse modo, antes de as funções psicológicas adquirirem a base social e regular, via pensamento, a conduta, elas pertencem ao princípio afetivo, no qual a interação é estruturada subjetivamente pelas emoções. A transformação dos fatores de ordenação e regulação da conduta, do meio social para o psicológico, altera o referencial da função reguladora da conduta; isso acontece através do aumento da capacidade de abstração - processo cognitivo no qual um fenômeno se torna objeto de reflexão, passível de análise e de causalidade - das interações realizadas no contexto sociocultural, em que o valor da experiência relacional pode ter como a parte principal conteúdos cotidianos e científicos (VYGOTSKY, 1999; BAZERMAN, 2004; MIANO, 2004).

A linguagem, produto de um corpo consolidado de conhecimento humano, serve de instrumento de mediação entre o campo subjetivo e o objetivo, possibilitando tornar estável a distinção, a organização e a manifestação, em palavras, das 
A função social da literatura na educação infantil: produção de sentido e desenvolvimento humano

Angelo Antonio Puzipe Papim

sensações e percepções relacionadas à realidade. Nesse sentido, a linguagem, em termos de desenvolvimento sociocultural, apoia as configurações de ensino, aproximando, de forma realista e autêntica, as oportunidades de os alunos explorarem e direcionarem o seu próprio aprendizado. Nas interações de ensino e aprendizagem, o conhecimento orienta professor e aluno a trabalharem em cooperação, uma vez que ele possui uma estrutura organizada que pode ser aprendida progressivamente no fazer (WERTSCH; STONE, 1985; WERTSCH; BIVENS, 1992).

A ação de ensinar por meio da literatura confere ao leitor, durante a atividade leitora, um gradual aprendizado do caráter mediador da linguagem. As experiências de ensino envolvendo literatura, por exemplo, demostram que as crianças adquirem a linguagem pela exploração e, principalmente, pela interação dialógica com o adulto. $\mathrm{Na}$ interação com o adulto, a criança vivencia a correspondência da palavra com a sua função social, marcando o princípio do processo de abstração e produção do sentido da palavra (WERTSCH, 2007; BRUNER, 1975).

De acordo com Vygotsky (2017), a palavra, para ser um mediador simbólico, passa por três etapas: os amontoados sincréticos, quando o sentido da palavra é oriundo da relação direta com os fenômenos sociais que provocam uma impressão imediata de sentido; a formação por complexo, na qual os fenômenos diretamente relacionados à palavra começam a ser organizados como parte de uma corrente de significados separados entre si, porém, associados, pois não há autonomia na psique do plano sociocultural; e, por fim, a formação de conceitos, a qual se configura pelo uso da palavra, aliado à função psíquica de abstração, entre outras, com a capacidade de representar, em palavras, sínteses dos fenômenos presentes no contexto sóciohistórico e cultural.

A palavra não está privada das graças da cultura e da história. Enquanto ferramenta de mediação simbólica, ela se mantém flanqueada, de um lado, pelas funções sociais, e, de outro, pelas funções psicológicas. Assim, o seu valor simbólico está vinculado aos acontecimentos e às ideias, ambos demandando a necessidade de organização sistemática da experiência material, para ser fonte produtora de sentido. A partir do social, a materialidade da palavra, intencionada para o 


\section{A função social da literatura na educação infantil: produção de sentido e desenvolvimento humano Angelo Antonio Puzipe Papim}

desenvolvimento humano, pode melhorar o funcionamento psicológico e vice-versa (RATNER, 1991; RETTING, 1990).

A linguagem, como descreve Ratner (2005), tem a função reguladora, permite a internalização de funções sociais e possibilita, na qualidade de função psicológica superior, a autorregulação da conduta, através da análise da palavra do outro e de sua própria. A palavra confere à interação social o instrumento inter/intrapsíquico necessário para a interação ativa. Por esse motivo, a literatura, na Educação Infantil, não serve ao propósito de ensinar a criança sobre literatura. Nessa etapa do desenvolvimento, é impossível aprender sobre a temática, todavia, o que se aprende, transitivamente, é o uso da palavra.

Nesse sentido, a ação pedagógica é a fonte que produz, no social, as bases para o desenvolvimento psicológico. Em virtude do exposto, com o objetivo de compreender o processo pedagógico envolvendo literatura infantil, realizou-se a análise descritiva do experimento de leitura de texto literário, empregando, para essa finalidade, um software pedagógico com história ilustrada e interativa, desenvolvida para o experimento, na qualidade de mediador do aprendizado da linguagem oral e escrita de crianças, na Educação Infantil.

\section{Apresentação e discussão dos dados}

Com a finalidade de desenvolver as funções psicológicas dos alunos, os professores podem ativamente transmitir a cultura. Esse processo precisa ser planejado, e a sua prática deve se dar em conformidade com os objetivos inicialmente traçados, o que faculta fazer narrações, através da mediação, a fim de descobrir o que a literatura tem a oferecer para compartilhar com a criança, favorecendo a internalização, a apropriação da cultura (PETIT, 2010).

Embora adultos e crianças possam utilizar o mesmo vocabulário, os menos experientes atribuem a uma palavra um sentido diferente do mais experiente, devido a suas habilidades com a língua, como recurso de mediação da leitura literária (DEBUS; JULIANO; BORTOLOTTO, 2016). O experimento a seguir foi elaborado com o objetivo de compartilhar os significados textuais, como indica Balça (2011), em 
A função social da literatura na educação infantil: produção de sentido e desenvolvimento humano

Angelo Antonio Puzipe Papim

processo de ensino dialógico de leitura, o qual caracteriza o leitor como um ator coconstrutor de sentido.

$\mathrm{Na}$ perspectiva do desenvolvimento cultural, a interação social é um dos elementos responsáveis, na formação do leitor, pela transmissão do significado (VYGOTSKY, 2003). A elaboração da atividade de leitura orienta a conduta do aluno e do professor. O planejamento da atividade, apresentado no Quadro 1, como linhaguia, enseja selecionar o conteúdo a ser trabalhado, os objetivos a serem desenvolvidos e alcançados e os procedimentos de como fazer; com efeito, são esses os elementos que permitem o diálogo e o compartilhamento de significados entre esses atores.

Quadro 1 - Planejamento da atividade leitora

\begin{tabular}{|c|c|c|}
\hline Conteúdos & Objetivos & Procedimentos \\
\hline $\begin{array}{l}\text { Percepção visual de imagens e } \\
\text { textos, linguagem oral e escrita. }\end{array}$ & $\begin{array}{l}\text { Ser capaz de selecionar as } \\
\text { imagens corretas da história, } \\
\text { para confeccionar o livro. Ser } \\
\text { capaz de resgatar e reconhecer } \\
\text { o conteúdo da história, assim } \\
\text { como as palavras. }\end{array}$ & $\begin{array}{l}\text { Organizar os alunos para ler e } \\
\text { explorar a história } A \text { Tata Tatu, } \\
\text { estimular os alunos a } \\
\text { representar os fatos em } \\
\text { interações dialógicas, } \\
\text { empregando o vocabulário da } \\
\text { história, para avaliação da } \\
\text { internalização do sentido das } \\
\text { palavras. }\end{array}$ \\
\hline
\end{tabular}

Fonte: Organizado pelo autor.

O experimento de leitura, visando a melhorar o desempenho dos alunos com a linguagem, em sala de aula, foi realizado com 12 alunos da Educação Infantil de uma escola municipal, pertencente a uma comunidade rural de uma cidade do interior de São Paulo, com idade entre 4 e 5 anos. Para a atividade central, foi desenvolvida a história A Tata Tatu (Figura 1). A história foi escrita e ilustrada pelo autor da pesquisa, 


\section{A função social da literatura na educação infantil: produção de sentido e desenvolvimento humano \\ Angelo Antonio Puzipe Papim}

com a finalidade de estimular a atividade leitora, ao retratar a realidade social dos alunos. A história possui uma série de situações-problema, de maneira que, a fim de avançar, é necessário resolvê-las. Como apoio auxiliar da atividade central, o professor trouxe o alfabeto móvel e imagens relacionadas à história e às palavras, com a finalidade de ofertar aos alunos possibilidades de interação.

Figura 1 - Capa da história - A tata tatu

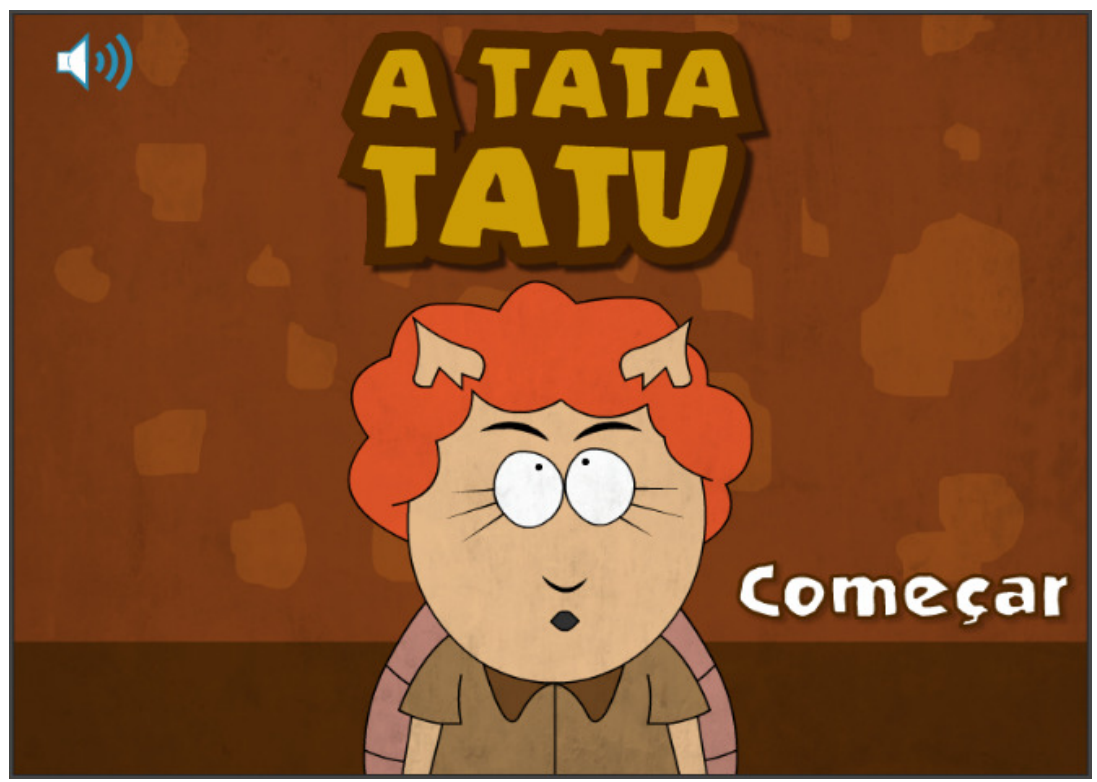

Fonte: Organizada pelo autor.

Para iniciar a atividade de leitura, o professor se senta no chão, com o material de apoio disposto à sua frente, e solicita aos demais alunos formarem um círculo, começando da esquerda para a direita, em torno do material. O professor indica aos alunos em qual posição eles devem se sentar. Os alunos próximos ao professor, sentados ao seu lado esquerdo e direito, são os que precisam de maior apoio para exercer a atividade, enquanto os mais distantes são os alunos que têm maior habilidade e são capazes de apoiar os demais, na atividade. A logística para estruturar a organização dos alunos no círculo integrou a etapa de elaboração da atividade, e nenhuma ação tomada pelo professor foi aleatória ou improvisada, mas sistematizada com previsibilidade. Esse item integra a preparação do roteiro desenvolvido para o experimento. 
A função social da literatura na educação infantil: produção de sentido e desenvolvimento humano

Angelo Antonio Puzipe Papim

É essencial, na atividade de mediação, o material pedagógico estar acessível a todos, uma vez que faz parte do contexto educacional o manuseio dos instrumentos, inclusive da linguagem, como condição imperativa do processo de internalização, o qual, no desenvolvimento cultural, é o meio pelo qual ocorre a aprendizagem (BAZZO, 2016). A organização, tanto dos alunos quanto do material pedagógico, constitui um elemento importante para desenvolver a função da leitura: obtenção de informação, estudo do texto, pretexto de leitura e leitura como fruição (BAZZO, 2016, p. 112).

Ao incentivar o aluno a percorrer a função da leitura, dentre os apoios oferecidos, o professor garante o cumprimento da atividade, orquestra a vontade e direciona a leitura dos alunos, mantendo-a dentro dos objetivos da atividade. Assim, é possível estimular a materialização da imaginação na palavra, e vice-versa, de cada aluno, bastando ao professor estar sensível à conduta leitora dos estudantes, como, por exemplo: quanto àqueles que se dispersarem, no decorrer da atividade, será necessária a intervenção do professor, a fim de ativar a atenção do aluno, com de sorte a direcioná-la para a execução da atividade.

O diálogo é um recurso pedagógico de grande valia, para engajar o aluno na vivência da atividade leitora, pois esta é mais importante para o desenvolvimento social e psicológico do aluno do que a mera execução das etapas constituintes da atividade. Por esse motivo, o professor tem que tornar as suas ações e as dos alunos parte do processo do processo de ensino e de aprendizagem - não com a intenção de repreender o aluno, mas de conscientizá-lo do fato de que sua ação pode ser denominada pela linguagem e por ela modificada, por via externa e por via interna. Em função disso, o professor concretiza a relação entre a sua ação e a ação do aluno com a linguagem, descrevendo-as à medida que vão ocorrendo. No exemplo do aluno disperso, o professor pode descrever o comportamento do aluno e the oferecer escolhas verbais de conduta, ao dizer: "Fulano ficou desatento, porque a atividade estava difícil", assim como dizer: "A atividade estava fácil e então decidi pensar em outra coisa". Independentemente da resposta do aluno, demonstra-se, com esse exemplo, o fato de, quanto mais se estabelecer a relação entre a linguagem e a ação, mais efetiva será a ação com a palavra (BAZZO, 2016). 


\section{A função social da literatura na educação infantil: produção de sentido e desenvolvimento humano Angelo Antonio Puzipe Papim}

Ao apresentar propostas de escolhas viáveis à conduta, o professor estará estimulando o uso da palavra, a fim de constituir na relação um determinado sentido ou efeito. É oportuno perceber que, no exemplo anterior, o professor não faz uma pergunta para o aluno sobre sua conduta, mas oferece a ele opção que a descreve. Isso posto, o professor precisa ter clareza do arranjo das palavras, ao verbalizar a ação, pois sua ação estará carregada de intenção, a qual necessita estar em consonância com os objetivos da atividade e favorecer o compartilhamento de significado e descoberta de significado (BAZZO, 2016). Muito antes de o professor associar a linguagem com a conduta e a palavra, faz-se necessário compreender se a descrição do contexto, pelo diálogo, será um exemplo encorajador e útil ao aluno. No entanto, estimulá-lo a empregar esse instrumento - a linguagem - é parte da atividade leitora.

No experimento, o professor apresenta aos alunos, em diferentes situações dialógicas, modelos com as palavras de produções de sentido. Ao organizar em círculo os alunos e o material pedagógico, o professor conversa com os alunos e explica o motivo dessa conduta. À medida que dialoga com as escolhas dos alunos, o professor orienta o aluno com a palavra, através de conversas úteis para compartilhar o significado relacionado a si, ao mundo e aos outros (BAZZO, 2016).

Quando todos estão aclimatados à organização, o professor dá início a outra etapa da atividade. Ele retira do material disposto no centro do círculo um tablete com a história interativa já iniciada na tela. Ele demonstra a cena de abertura para todos e encoraja os alunos a falarem o que estão pensando. Depois de uma conversa sobre a abertura, o professor clica em "começar", a fim de dar início à história (Figura 2). 
Figura 2 - Sequência de imagens da história

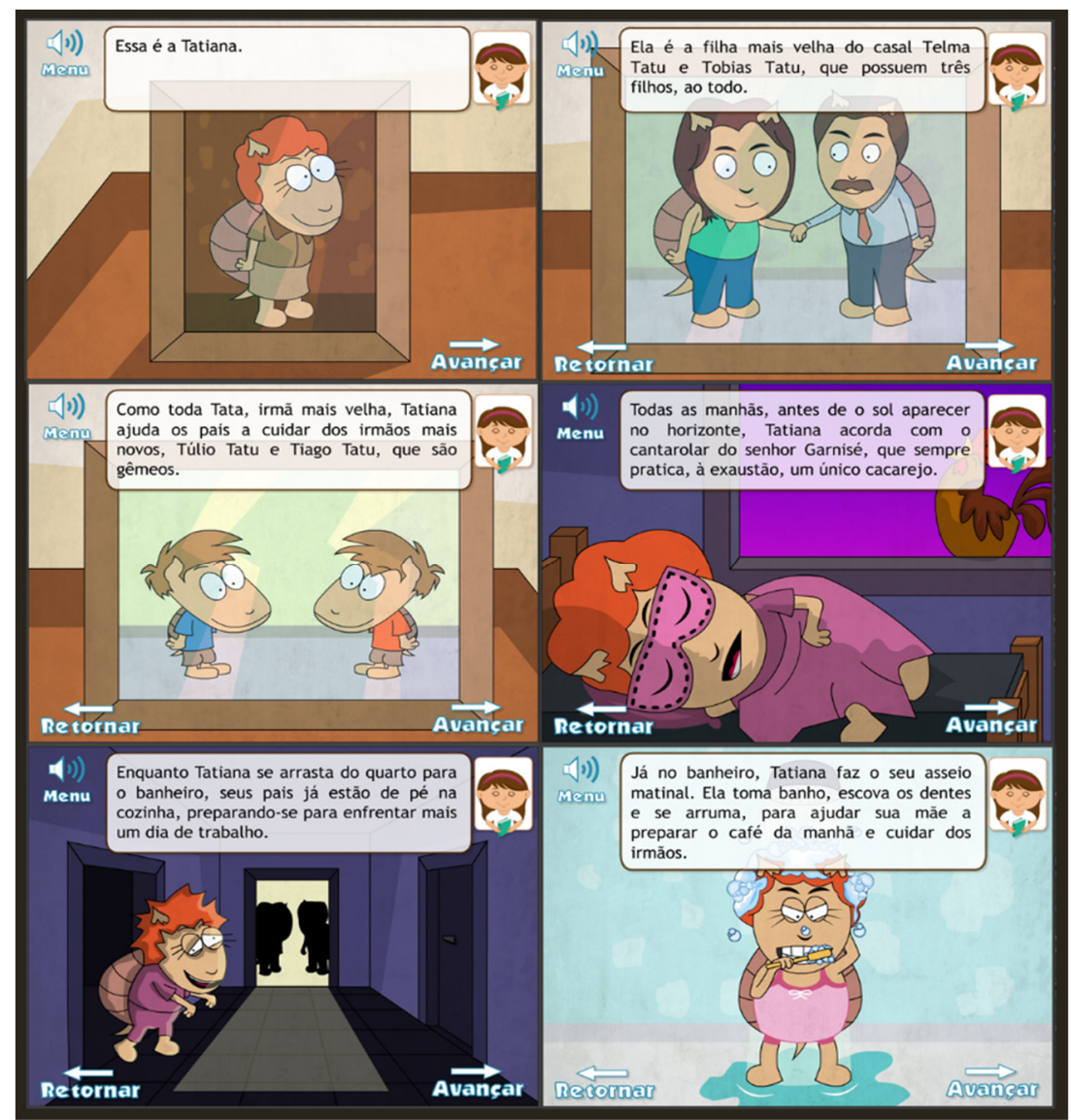

Fonte: Organizada pelo autor.

A atividade com o texto, no suporte digital, possui a finalidade de promover a função da leitura, estimulando os alunos a compreender a relação da linguagem com o contexto social e psicológico, estabelecendo a tríade: literatura - cultura -, sociedade - interação social - e autoconhecimento - equilíbrio psicológico -. Para isso, o professor mantém a estratégia inicial de usar os componentes da história, com a intenção de oferecer aos alunos escolhas que deverão ser realizadas, apoiadas no emprego da linguagem como instrumento, de modo a relacionar as palavras e a intenção do outro com a conduta pessoal (BAZZO, 2016).

Imagens, palavras, formas diversas compõem, a cada cena da história, um conjunto de elementos que precisam da cooperação do professor, para transformar esses significados da linguagem verbal e visual em processo de produção de sentido (VAN DER LINDER, 2011). O professor pode solicitar aos alunos imaginar qual a 


\section{A função social da literatura na educação infantil: produção de sentido e desenvolvimento humano Angelo Antonio Puzipe Papim}

finalidade de cada palavra, antes de demonstrar sua função, de maneira a fazer inferências: é interessante incentivar que os alunos conversem entre si, para se beneficiarem da intenção e conhecimento uns dos outros. Como enfatiza Bazzo (2016), a atividade leitora impulsiona a produção social de sentido, a imaginação e a criatividade e o devir, como fruição que rompe limites socioculturais.

Com a intenção de fazer os alunos olharem para a sua própria forma de pensar, fora o diálogo, a criança era convidada a ouvir a narradora da história e acompanhar a legenda - recurso interativo - (Figura 3), e, depois, também, a falar baixinho o que entendeu, sem atrapalhar os demais, todavia, ouvindo as suas próprias falas, no sentido de torná-las aptas a denominarem a sua própria conduta com as palavras.

Figura 3- Áudio e legenda

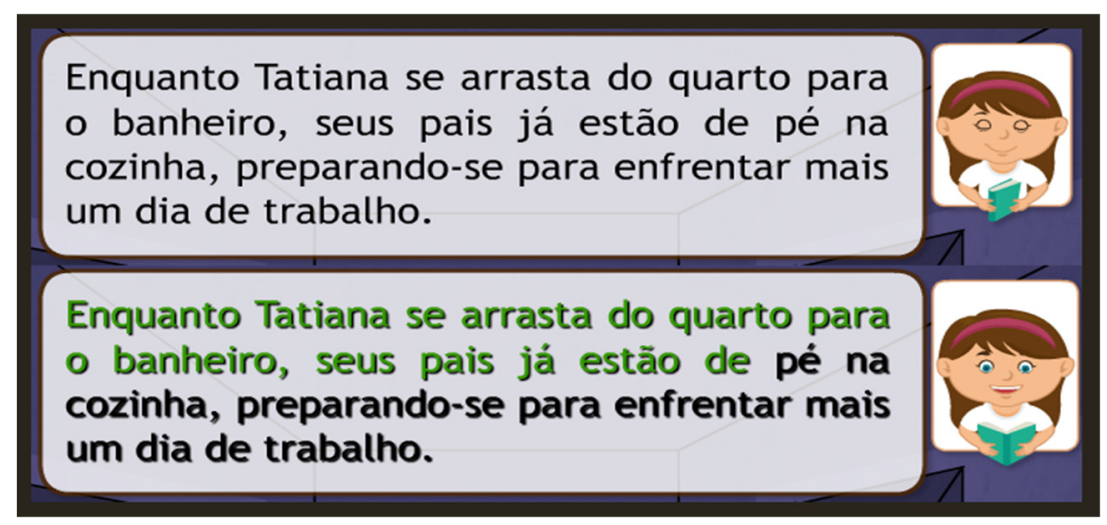

Fonte: Organizada pelo autor.

A história narra o dia a dia da Tatiana. No início da história, são focalizadas as atividades que ela desempenha sozinha; na sequência, as que ela precisa realizar, a fim de ajudar sua mãe com os afazeres e o cuidado com os irmãos. Há quatro situações-problema na história (Figura 4), cujo processo de resolução contribui com o objetivo de construir, com o protagonismo das crianças, o sentido de quatro palavras: amassar, procurar, assear e alimentar. A ação pedagógica, nessas quatro situaçõesproblema, foi intensificada, com a finalidade de descrever, com o maior detalhamento possível, a relação da palavra com o que estava acontecendo na tela. 
A função social da literatura na educação infantil: produção de sentido e desenvolvimento humano

Angelo Antonio Puzipe Papim

Figura 4 - Situações-problema

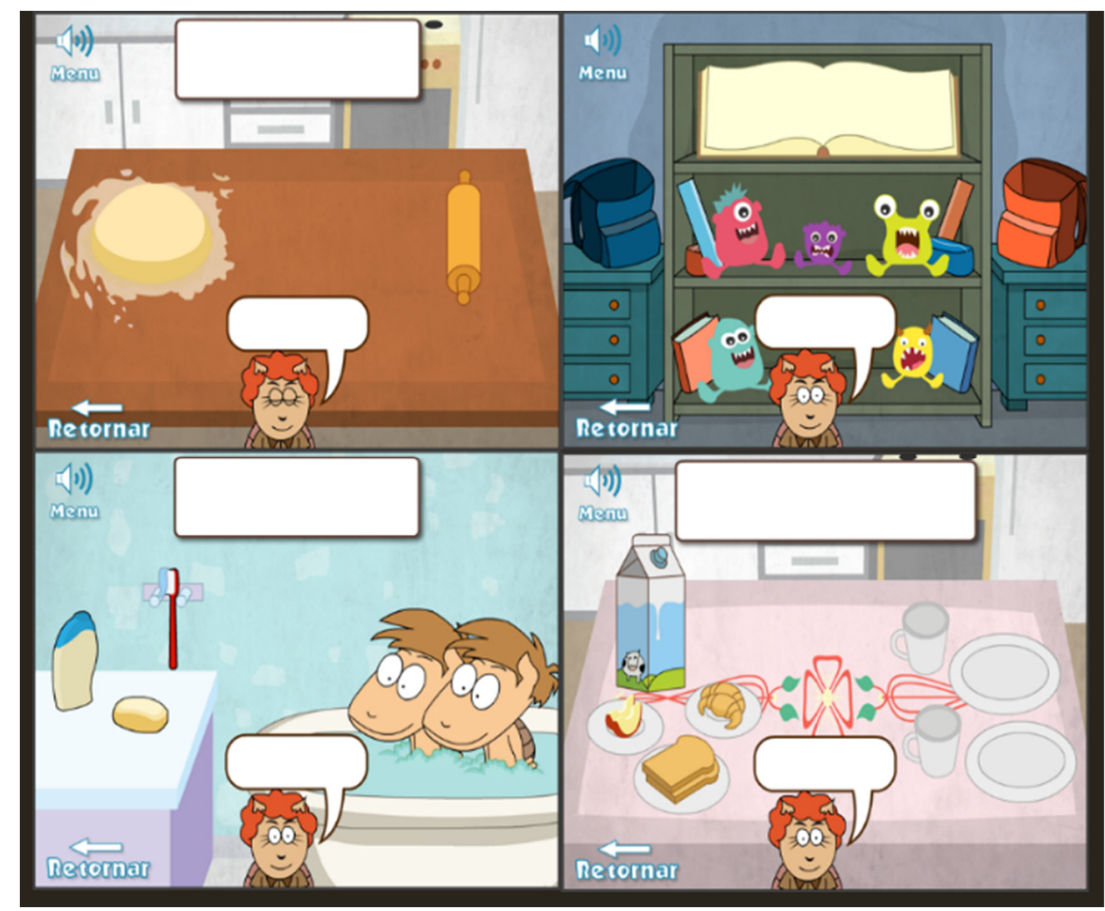

Fonte: Organizada pelo autor.

O professor não deve ter receio de descrever o comportamento do aluno, a fim de que ele compreenda sua ação, através de sua descrição verbal. Caso uma criança se disperse, descreva a sua conduta em detalhes e indique a ela a conduta que deve realizar. O espaço destinado a exercer a função da leitura se imbrica ao movimento dialógico, a partir do qual a criança pode experimentar suas compreensões, abstraindo sentido das ações efetivadas, enquanto o professor, em cooperação com a criança, oferece os apoios necessários para o conhecimento ser produzido no social e no psicológico, assegurando à ação pedagógica a ZDI, na qual os conceitos novos precisam ser relacionados a uma ação e a um conceito já conhecidos (BAZZO, 2016; VYGOTSKY, 2000).

Manter a criança dentro da ZDI deve ser uma preocupação do professor, ao concretizar a ação pedagógica, já que, ao estabelecer espaço de desenvolvimento, ele contextualiza o significado presente no conceito, demonstrando sua função pela palavra, no contexto sociocultural. Com a intenção de tornar claro o significado, inserem-se quantas contradições, apoios, negociações etc. forem necessários. No 


\section{A função social da literatura na educação infantil: produção de sentido e desenvolvimento humano Angelo Antonio Puzipe Papim}

experimento, por exemplo, para facilitar a internalização do significado pelas crianças, o professor inseriu na atividade o alfabeto silábico, organizando as palavras uma a uma, acompanhando a sequência na qual cada uma aparece na história e explicando com outros exemplos, pela linguagem visual, o que significava cada palavra.

A parte final da intervenção pedagógica consistiu no processo de avaliação dos alunos. O professor solicitou que todos se levantassem e os alunos em fila assumissem uma posição, no lado oposto da mesa. Durante o deslocamento dos alunos, ele ouviu sussurros individuais de alguns alunos, mas não soube identificar o que diziam. O professor dispôs sobre a mesa uma almofada, um estojo vazio, um punhado de lápis de cor, uma escova de cabelo, um boneco, um cavalo e um gramado feito de tecido. Na medida em que ia dispondo o material sobre a mesa, o professor falava para si mesmo a descrição do material. Após ter feito isso, ele incentivou os alunos, em parceria, a recriar a cena da história na qual apareceram as quatro palavras: amassar, procurar, asseare alimentar. Para isso, as crianças poderiam falar entre si e consigo mesmas e descrever suas ações, antes de executá-las.

Um aluno, assim que ouviu a instrução do professor, disse: "Almofada" e bateu com as duas mãos sobre ela. Outro, largando as mãos sobre o corpo, disse em voz baixa: "É mesmo, ele amassou ela". Outro olhou para o professor e informou: "Já fizemos a primeira atividade, pois ele amassou a almofada". Um aluno, que estava ao seu lado, ria, enquanto o outro se escondia, acanhado. O professor pediu a todos que amassassem a almofada do seu jeito e a descrevessem, enquanto executavam sua ação. Todos fizeram.

Para a segunda tarefa, o professor solicitou que todos participassem e, em grupo, procurassem o material mais adequado para guardar no estojo. $O$ aluno mais acanhado apontou para o lápis, olhou para os demais e disse: "Devemos guardar isso". Dois concordaram, acenando com a cabeça. Afirmou que queria guardar o cavalo, mas foi logo censurado, com a justificativa de que não se pode levar brinquedo para a escola. Depois de um diálogo produtivo entre os alunos, eles guardaram os lápis de cor no estojo e o entregaram para o professor. Todos tiveram dificuldade de relacionar a escova de cabelo com o boneco, sugerindo pentear o cabelo como parte 
A função social da literatura na educação infantil: produção de sentido e desenvolvimento humano

Angelo Antonio Puzipe Papim

do asseio. O professor precisou mediar o significado e a conduta dos alunos. A última palavra foi a mais fácil para os alunos explorarem o conceito. Mesmo assim, um perguntou para si: "Isso é grama? Se for, o cavalo come." Outro disse: "Só pode ser esses dois juntos, o cavalo não mastiga mais nada, apenas grama." No final, todos concordaram e descreveram que o cavalo se alimenta de grama. A última atividade dessa etapa foi escrever as quatro palavras; para isso foi utilizado o acervo cultural disponibilizado pelo professor, inclusive o tablet. A atividade foi realizada com a cooperação de todos. O professor destacou a importância das interações para escolher as possibilidades disponíveis. Outra estratégia adotada com o objetivo de avaliação foi empregar o próprio discurso do aluno, diante de situações semelhantes, para resolvê-las.

$\mathrm{Na}$ opinião do professor, a parte mais difícil do processo foi avaliar a internalização das palavras compartilhadas na atividade, e se a linguagem como ferramenta de comunicação faz parte da elaboração de entendimento da criança. A percepção do professor, durante os diálogos com a crianças, consistia em analisar se houve a transferência de significado da palavra do adulto para a criança, da cultura para o psiquismo, ou se a conduta do aluno ainda depende de uma ação externa, social, para produção de sentido.

\section{CONSIDERAÇÕES FINAIS}

Os professores, ao encorajar as crianças a empregar a palavra como recurso de produção de sentido, intensificou a capacidade de transportar o significado presente em uma conduta social para a pessoal. Não há possibilidade de desenvolver as capacidades humanas das crianças sem a ocorrência, no presente, de interações sociais. Através delas, a aprendizagem da linguagem é possível. A literatura se mostra um instrumento adequado para esse objetivo. A ação pedagógica, por uma série de mediações, rompe e ultrapassa os limites biológicos da criança. Nas interações dialógicas, na escola, a conduta da criança é intencionalmente influenciada pela conduta do professor, movimento precursor do desenvolvimento humanizado. Em vista disso, o professor atua de modo a elaborar processos e ações pedagógicas com conteúdos culturais que precisam ser passados aos alunos, por meio de vivências. A 


\section{A função social da literatura na educação infantil: produção de sentido e desenvolvimento humano Angelo Antonio Puzipe Papim}

linguagem escrita é uma conduta social caracterizada por ser consequência direta de processos de leitura e internalização do projeto pedagógico. O modelo de conduta social com linguagem expressa no adulto origina na criança a base para lidar com a linguagem.

Assim, a literatura, a linguagem e as interações dialógicas possibilitam à criança se apropriar das palavras e manejá-las, no âmbito sociocultural, enquanto etapa importante para o seu desenvolvimento psíquico. A ação pedagógica intencionada desenvolve, progressivamente, a capacidade da criança de utilizar a linguagem, de maneira a clarear os pensamentos, moldar a conduta social e compartilhar significantes culturais como produção cooperativa de sentido. Embora esta investigação tenha obtido um resultado tímido, cujo aperfeiçoamento demanda uma experimentação feita em um período de tempo maior que um único encontro, não se pode negar a importância da literatura enquanto necessidade pedagógica para formação, não só de leitores, mas de seres humanos, ou seja, a aprendizagem da linguagem, no sentido de processo de humanização. Assim, o compartilhamento da palavra, que favorece a regulação da conduta, seja na elaboração dos objetivos e estratégias pedagógicas no ato de ensino, seja na atuação do professor sobre a aprendizagem das crianças, está na base das funções sociais, psicológicas e pedagógicas. É um bem cultural que precisa ser passado as novas gerações, por meio da leitura dos textos literários. 
A função social da literatura na educação infantil: produção de sentido e desenvolvimento humano

Angelo Antonio Puzipe Papim

\section{REFERÊNCIAS}

ARSHAD, M.; CHEN, W. Vygotsky's socio-cultural theory of literacy Scaffolding children to read and write at an early age. Journal of the Humanities of Indonesia, v. 11, p. 319-334, 2009.

BALÇA, A. M. F. M. C. P. Projetos e atividades de promoção da leitura e de formação de leitores. Ensino em Re-vista, v.18, n. 1, 2011.

BARROS, D. L. P.; FIORIN, J. L. Dialogismo, polifonia, intertextualidade: em torno de Bakhtin. São Paulo: Editora da Universidade de São Paulo, 1994.

BAZERMAN, C. Intertextualities: Volosinov, Bakhtin, Literary Theory, and Literacy Studies. In: BALL, A. F.; FREEDMAN, S. W. Bakhtinian Perspectives on Language, Literacy, and Learning. Nova York: Cambridge University Press, 2004.

BAZZO, J. L. S. Literatura e infância: fruição ou pretexto? In: DEBUS, E.; JULIANO, D. B.; BORTOLOTTO, N. Literatura infantil e juvenil: do literário a outras manifestações estéticas. Tubarão: Copiart Unisul, 2016.

BRUNER, J.S. Acts of meaning. Cambridge: Harvard University Press, 1975.

BYRNES, H. Advanced Language Learning: The Contribution of Halliday and Vygotsky. London: Continuum, 2006.

CULLER, J. Teoria Literária: uma introdução. São Paulo: Beca Produções Culturais, 1999.

DANIELS, H. Vygotsky Pedagogy. New York: Routledge, 2016.

ENGESTROM, E. Learning by Expanding: An Activity-Theoretical Approach to Developmental Research. New York: Cambridge University Press, 2014.

ENGESTROM, E. Studies in Expansive Learning: learning what is not yet there. New York: Cambridge University Press, 2016.

INGOLD, T. Anthropology and/as Education. London: Routledge, 2017.

JULIANO, D. B. Leitura literárias e de outras linguagens: a mediação em perspectiva. In: DEBUS, E.; JULIANO, D. B.; BORTOLOTTO, N. Literatura infantil e juvenil: do literário a outras manifestações estéticas. Tubarão: Copiart Unisul, 2016.

KOZULIN, A. Vygotsky's psychology: a biography of ideas. Cambridge: Harvard University Press, 1990.

KOZULIN, A. Psychological Tools: A Sociocultural Approach to Education. Cambridge: Harvard University Press, 1998.

KOZULIN, A.; GINDIS, B. Sociocultural Thinking and Education of Children with Special Needs: From Defectology to Remedial Pedagogy. In: DANIELS, H.; COLE, M.; WERTSCH, J. V. The Cambridge Companion to Vygotsky. New York: Cambridge University Press, 2007.

MIANO, A. A. Voices in Dialogue - Hybridity as Literacy, Literacy as Hybridity: Dialogic Responses to a Heteroglossic World. In: BALL, A. F.; FREEDMAN, S. W. Bakhtinian Perspectives on Language, Literacy, and Learning. Nova York: Cambridge University Press, 2004.

MILLER, R. Vygotsky in Perspective. New York: Cambridge University Press, 2011.

MOEN, A.; NES, S. Consolidating work Descriptions: Creating Shared Knowledge Objects. In: MOEN, A.; MORCH, I. Collaborative Knowledge Creation: Practices, Tools, Concepts. Rotterdam: Sense Publishers, 2012.

MORATO, E. M.; KOCH, I. V. Linguagem e cognição: os (des) encontros entre a lingüística e as ciências cognitivas. Cadernos de Estudos Linguísticos, v. 44, p. 85-92, 2011.

PETIT, M. A transmissão cultural para tornar o mundo habitável. In: ROSING, T. M. K.;

BURLAMAQUE, F. V. De casa e de fora, de antes e agora: estudos de literatura infantil e juvenil. 
A função social da literatura na educação infantil: produção de sentido e desenvolvimento humano Angelo Antonio Puzipe Papim

Passo Fundo: Ed. Universidade de Passo Fundo, 2010.

PINO, A. As marcas do humano: as origens da constituição cultural da criança na perspectiva de Lev S. Vigotski. São Paulo: Cortez, 2005.

RATNER, C. Vygotsky's Sociohistorical Psychology and its Contemporary Applications. New York: Springer Science, 1991.

RATNER, C. Cultural Psychology: A Perspective on Psychological Functioning And Social Reform. New Jersey: Lawrence Erlbaum Associates, 2005.

RETTIG, S. The discursive social psychology of evidence: symbolic construction of reality. New York: Springer Science, 1990.

SHAFFER, D. R.; KIPP, K. Developmental Psychology: Childhood and Adolescence. 8. ed. Wadsworth: Cengage Learning, 2010.

SMAGORINSKY, P. Vygotsky and Literacy Research: A Methodological Framework. Boston: Sense Publishers, 2011.

TODOROV, T. A conquista da América: a questão do outro. São Paulo: Martins Fontes, 1993.

VAN DER LINDEN, S. Para ler o livro ilustrado. São Paulo: Cosac Naify, 2011.

VYGOTSKY, L. S. The genesis of higher mental functions. In: WERTSCH, J. V. The concept of activity in Soviet psychology. Armonk: Sharpe, 1981.

VYGOTSKY, L. S. The Collected Works of L. S. Vygotsky: Scientific Legacy. 1. ed. New York: Springer, 1999.

VYGOTSKY, L. S. Obras escogidas: tomo III. Madrid: Tomás Bretón, 2000.

VYGOTSKY, L. S.; LURIA, A. R.; LEONTIEV, A. N. Linguagem, Desenvolvimento e Aprendizagem. 11. ed. São Paulo: Ícone, 2010.

WELLS, G. Dialogic inquiry: toward a sociocultural practice and theory of education. Cambridge: Cambridge University Press, 1999.

WERTSCH, J.V. Voices of the mind: a sociocultural approach to mediated action. 4. ed. Cambridge: Harvard University Press, 1997.

WERTSCH, J. V. Mediation. In: DANIELS, H.; COLE, M.; WERTSCH, J. V. The Cambridge companion to Vygotsky. New York: Cambridge University Press, 2007.

WERTSCH, J. V. From social interaction to higher psychological processes. Human Development, v. 51, p. 66-79, 2008.

WERTSCH, J. V.; BIVENS, J. The social origins of individual mental functioning; Alternatives and perspectives. Quarterly Newsletter of Laboratory of Comparative Human Cognition, v. 14, n. 2, p. 35-44, 1992.

WERTSCH, J. V.; STONE, C. A. The concept of internationalization in Vygotsky's account of the genesis of higher mental functions. In: WERTSCH, J. V. Culture, communication, and cognition: Vygotskian perspectives. New York: Cambridge University Press, 1985. 